\title{
Study on dynamic modulus of asphalt mixture in cold region under rotary accelerated loading
}

\author{
Li Zhu ${ }^{1}$, Jin $\mathrm{Li}^{1 *}$, Miaozhang $\mathrm{Yu}^{1}{ }^{1}$, Di Dong ${ }^{1}$, and Xinzhuang Cui ${ }^{2}$ \\ ${ }^{1}$ Shandong jiaotong University, School of Civil Engineering, 250357 Jinan, China \\ ${ }^{2}$ Shandong University, School of Civil Engineering, 250061 Jinan, China
}

\begin{abstract}
In order to study the evolution law of mechanical properties of asphalt pavement mixture in cold regions under long-term load, the rotary accelerated loading equipment was used to carry out a total of 500,000 accelerated loading tests on the full-scale pavement, and the dynamic modulus test of the mixture before and after wheel load was carried out respectively. The master curve of dynamic modulus and dynamic modulus ratio (dynamic modulus value after wheel load / dynamic modulus value before wheel load) of the mixture at $-20^{\circ} \mathrm{C}$ were established to predict the long-term mechanical response of the mixture at low temperature. The results show that: low-frequency (or high temperature) has a more significant effect on the viscoelastic properties of the asphalt mixture. In the conversion frequency range of $1.6 \times 10^{-3} \sim 1.6 \times 10^{2} \mathrm{~Hz}$, the dynamic modulus ratio decreases with the increase of frequency, and the maximum ratio is 0.62 when the frequency is $1.6 \times 10^{-3} \mathrm{~Hz}$, which indicates that the high frequency (low temperature) has little effect on the performance of asphalt mixture. This study can be used as a theoretical reference for the structural design and performance optimization of asphalt pavement in cold regions.
\end{abstract}

\section{Introduction}

Accelerated loading equipment can be used to simulate the damage of road surface quickly caused by actual traffic load in several years, and its full-scale accelerated loading test is the most effective and accurate way to realize the fatigue process of asphalt pavement. In the 1980s, in order to promote the asphalt research results of the SHRP program, the United States paved the test road and carried out a long-term ring accelerated loading fatigue test, during which the road performance index of asphalt pavement was monitored and analyzed, and the performance evaluation specification of hot mix asphalt pavement was formulated ${ }^{[1]}$. Sirin et al conducted five test sections through a heavy vehicle simulator to estimate the rutting of Florida road surface ${ }^{[2]}$. Choubane et al used accelerated loading test equipment to evaluate the longterm performance of high-performance asphalt pavement with coarse and fine aggregate gradation ${ }^{[3]}$. Li Jin, $\mathrm{Hu}$ Peng and others from Shandong Jiaotong University ${ }^{[4]}$ have paved the indoor full-scale test road, and systematically analyzed the fatigue damage characteristics of typical asphalt pavement in Shandong under the combined operation of main and driven wheels by using the self-developed double axle straight road acceleration loading equipment.

It is limited to evaluate the mechanical or fatigue characteristics of asphalt pavement by accelerated loading test, so it is necessary to combine it with indoor test and theoretical analysis. Guo et $\mathrm{al}^{[5]}$ believe that applying the

\footnotetext{
* Corresponding author: Jin Li: sdzblijin@ $@ 163 . c o m$
}

data obtained from accelerated loading test to computer simulation theory can evaluate the fatigue performance of pavement correctly and effectively. The dynamic modulus of asphalt mixture is an important index to characterize its dynamic characteristics. The dynamic modulus test of the specimens before and after accelerated loading can be used to accurately estimate and evaluate the long-term mechanical properties of asphalt pavement. Many scholars at home and abroad have studied the dynamic modulus of asphalt mixture. Clyne ${ }^{[6]}$ takes the actual asphalt viscosity as the most important prediction variable and uses the form of the S-shaped function model to establish the modified dynamic modulus model of asphalt mixture, which greatly improves the rationality of model prediction under extreme temperature conditions. Wang dianchen ${ }^{[7]}$ analyzed the factors influencing the dynamic modulus of asphalt mixture through the indoor test of dynamic modulus of asphalt mixture and found that the loading frequency and temperature have a great influence on the dynamic modulus. Nifujian and Huangzhujiang ${ }^{[8-9]}$ studied the dynamic modulus characteristics of different types of asphalt mixtures and analyzed the influence of confining pressure, frequency, and temperature on the dynamic characteristics of asphalt mixtures. Wang Weiping and Wei Jincheng ${ }^{[10-11]}$ have found that the mechanical response of asphalt pavement is different under different temperature and traffic conditions, which shows certain regularity, and the regularity can be described by a mathematical model. $\mathrm{Wu}$ Rongdong et al. ${ }^{[12]}$ established the master curve of dynamic modulus of epoxy asphalt OGFC, analyzing and putting forward the performance of "high-temperature 
non-melting, low-temperature non-brittle". Yu Lei and et $\mathrm{al}^{[13]}$ analyzed the influence of bitumen-aggregate ratio on the high temperature stability of rubber asphalt mixture by establishing the master curve of rubber asphalt mixture with different bitumen-aggregate ratio.

In this paper, the indoor asphalt test road is paved, and the rotary accelerated loading equipment (ALT-R100) with independent intellectual property rights of Shandong Jiaotong University is used for indoor accelerated loading tests. The equipment can simulate the actual stress state of pavement more truly, evaluate the fatigue damage of pavement correctly, and test the dynamic modulus of asphalt mixture under long-term load with corresponding test means. At present, there are few studies on the dynamic modulus of asphalt mixture under accelerated loading, so it is necessary to further study.

\section{Raw material inspection}

SBS modified asphalt with good low-temperature performance is selected as the test asphalt material. Basalt with good adhesion to asphalt is selected as the coarse aggregate, and basalt machine-made sand is used as the fine aggregate $(<3 \mathrm{~mm})$. The test indexes of all aggregates meet the specifications, and the test parameters of asphalt are shown in table 1 .

The coordination of the SBS modified AC-20 asphalt mixture is shown in table 2 below. The asphalt aggregate ratio is based on the practical experience in cold regions and the gradation design of the test. After calculation, the optimum asphalt aggregate ratio of the modified asphalt mixture is $5.2 \%$, and all the test indexes of the mixture are verified to be qualified.

Table 1. Test parameters of asphalt

\begin{tabular}{|c|c|c|}
\hline \multirow{2}{*}{ Test index } & \multirow{2}{*}{ Unit } & SBS modified asphalt \\
\hline & & Test parameters \\
\hline Penetration $\left(25^{\circ} \mathrm{C}\right)$ & $0.1 \mathrm{~mm}$ & 51.9 \\
\hline Softening point & ${ }^{\circ} \mathrm{C}$ & 71.8 \\
\hline Ductility $\left(5^{\circ} \mathrm{C}, 5 \mathrm{~cm} / \mathrm{min}\right)$ & $\mathrm{cm}$ & 31 \\
\hline Density $\left(15^{\circ} \mathrm{C}\right)$ & $\mathrm{g} / \mathrm{cm}^{3}$ & 1.020 \\
\hline Relative density $\left(25^{\circ} \mathrm{C}\right)$ & / & 1.024 \\
\hline \multirow{2}{*}{$\begin{array}{c}\text { Elastic recovery }\left(5^{\circ} \mathrm{C}\right) \\
\text { Storage stability segregation, } 48 \mathrm{~h} \text { softening point } \\
\text { difference }\end{array}$} & $\%$ & 69 \\
\hline & ${ }^{\circ} \mathrm{C}$ & 1.2 \\
\hline Mass loss & $\%$ & -0.16 \\
\hline Residual penetration ratio & $\%$ & 79.1 \\
\hline $\begin{aligned} & \text { Residual } \\
\text { ductility } & \left(5^{\circ} \mathrm{C}, 5 \mathrm{~cm} / \mathrm{min}\right)\end{aligned}$ & $\mathrm{cm}$ & 16.4 \\
\hline
\end{tabular}

Table 2. Target mix proportion of asphalt mixture AC-20 /\%

\begin{tabular}{cccccc}
\hline $\begin{array}{c}\text { Gravel (10 20 } \\
\mathrm{mm})\end{array}$ & $\begin{array}{c}\text { Gravel (10 15 } \\
\mathrm{mm})\end{array}$ & $\begin{array}{c}\text { Gravel (5 10 } \\
\mathrm{mm})\end{array}$ & $\begin{array}{c}\text { Gravel (3 5 } \\
\mathrm{mm})\end{array}$ & $\begin{array}{c}\text { Machine-made } \\
\text { sand }\end{array}$ & Mineral powder \\
\hline 38 & 8 & 11 & 9 & 31 & 3 \\
\hline
\end{tabular}

\section{2 determination of accelerated loading scheme}

Basic test conditions: Test axle load: $650 \mathrm{~kg}$; loading speed: $13.1 \mathrm{~km} / \mathrm{h}$; loading times: 500000 ; test set temperature: $15^{\circ} \mathrm{C}$.

\section{Test implementation}

\subsection{Paving of test road}

The indoor full-scale accelerated loading structural model test road is 4 meters long and 1 meter wide. The combination mode of design pavement structure model is $4 \mathrm{~cm} \mathrm{AC-20} \mathrm{in} \mathrm{the} \mathrm{upper} \mathrm{layer} \mathrm{and} 6 \mathrm{~cm} \mathrm{AC-25}$ in the lower layer, and the base is $36 \mathrm{~cm}$ cement stabilized macadam in the road structure hall, as shown in Figure 1.

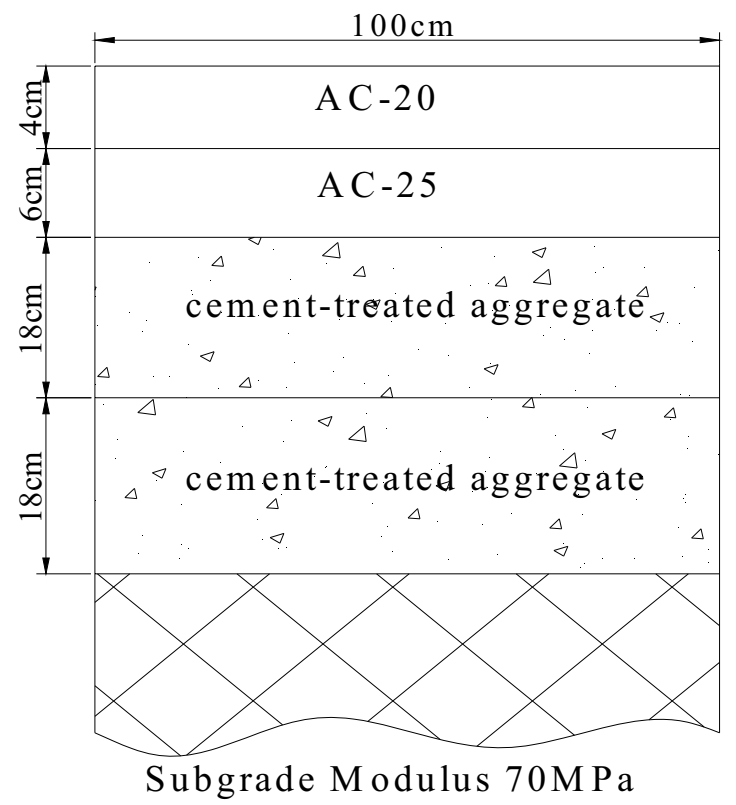

Figure 1. Asphalt pavement structure type of test road 
equipment to simulate the environment in the cold area. First, the temperature of the environment box of the rotary acceleration loading system is controlled at $-15^{\circ} \mathrm{C}$, and then the temperature was controlled for six hours to stabilize the road surface temperature. Finally, the equipment was started, and the self-developed ALT-R100 acceleration loading system is used to load continuously on the paved indoor full-scale test pavement, with a total of 500,000 Acceleration loading test of shaft number.

\section{3 dynamic modulus test scheme}

\subsection{1 specimen preparation}

(1) Sample before wheel loading: SBS modified AC-20 mixture specimen formed by rotary compactor.

(2) Sample after wheel loading: after the accelerated loading test of full-scale test road based on cold area is completed, core samples are drilled in the loading area of test road.

All the samples are $170 \mathrm{~mm}$ high and $150 \mathrm{~mm}$ diameter cylinders. The core samples with the diameter of (100 \pm 2$)$ $\mathrm{mm}$ were drilled on the cylinder specimens before and after the wheel load by the coring machine, and the irregular parts at both ends of the core samples were cut off by the cutting machine under the condition of controlling the height of the specimen to be $(150 \pm 2.5) \mathrm{mm}$.

\subsubsection{Scheme}

In the actual service process of pavement in a cold region, the modulus of asphalt mixture is mainly affected by the temperature change and heavy traffic. The dynamic modulus of the mixture before and after the wheel load was tested by a simple performance testing machine (AMPT). Under the condition of no confining pressure, half normal wave axial compressive stress was applied by controlling the test temperature and loading frequency. The loading time was $0.1 \mathrm{~s}$ and the intermittent time was $0.9 \mathrm{~s}$. The test was carried out according to the control temperature from low temperature to high temperature: $10^{\circ} \mathrm{C}, 5^{\circ} \mathrm{C}, 20^{\circ} \mathrm{C}, 35^{\circ} \mathrm{C}$ and $50^{\circ} \mathrm{C}$, and the frequency changes from high frequency to low frequency: $25 \mathrm{~Hz}$, $10 \mathrm{~Hz}, 5 \mathrm{~Hz}, 1 \mathrm{~Hz}, 0.5 \mathrm{~Hz}$ and $0.1 \mathrm{~Hz}$.

\section{Test results and analysis}

\subsection{Development of dynamic modulus with loading frequency}

In order to reflect the law of material modulus changing with frequency intuitively, based on the test data, taking the loading frequency as the variable, the dynamic modulus changing with the loading frequency before and after the wheel load of the mixture at each temperature ($10^{\circ} \mathrm{C} \sim 50^{\circ} \mathrm{C}$ ) is sorted and plotted, as shown in figure 2 .

After 500,000 times of axle load based on accelerated loading test at $-15^{\circ} \mathrm{C}$, it can be found that the modulus of unfatigued asphalt mixture is greater than that of fatigue asphalt mixture after wheel load of accelerated loading equipment at the same temperature, and the change of modulus tends to be slow and steady under high frequency. Due to the aging of asphalt concrete, crushing of coarse aggregate, and compaction of fine aggregate, the structure of the asphalt mixture is damaged, resulting in the decrease of material stiffness and modulus.

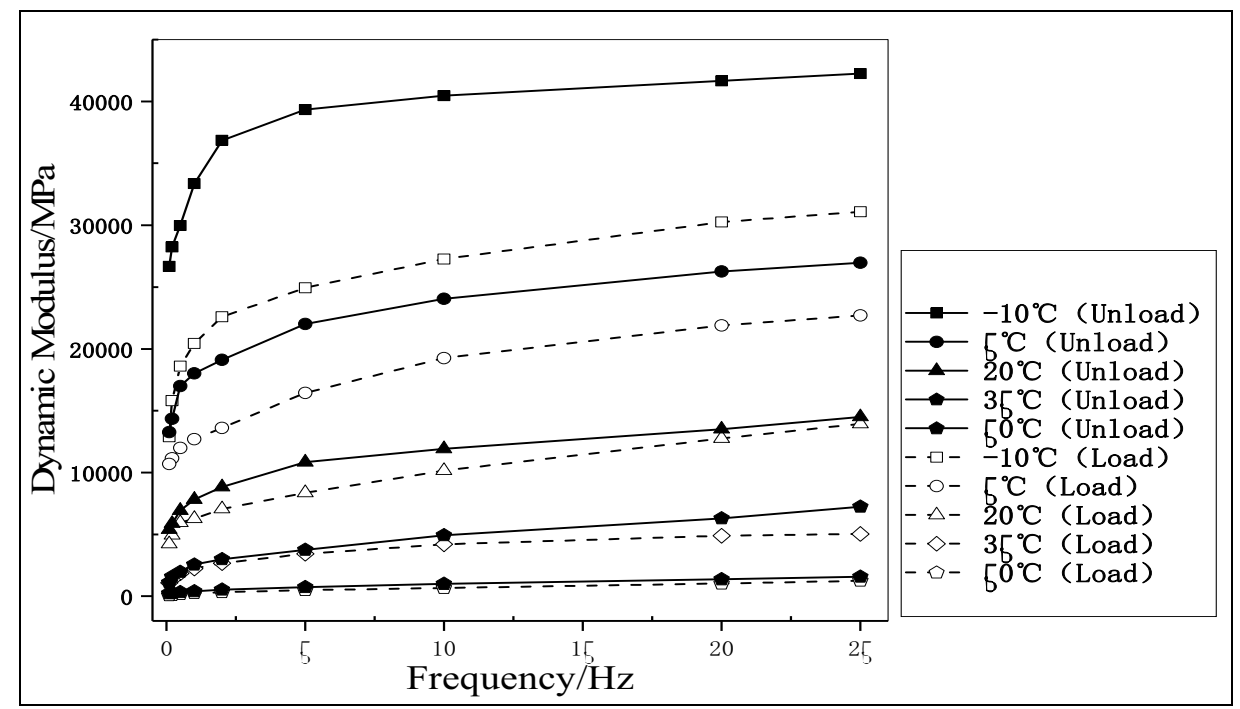

Figure 2. Dynamic modulus of mixture with loading frequency curve at different temperatures 


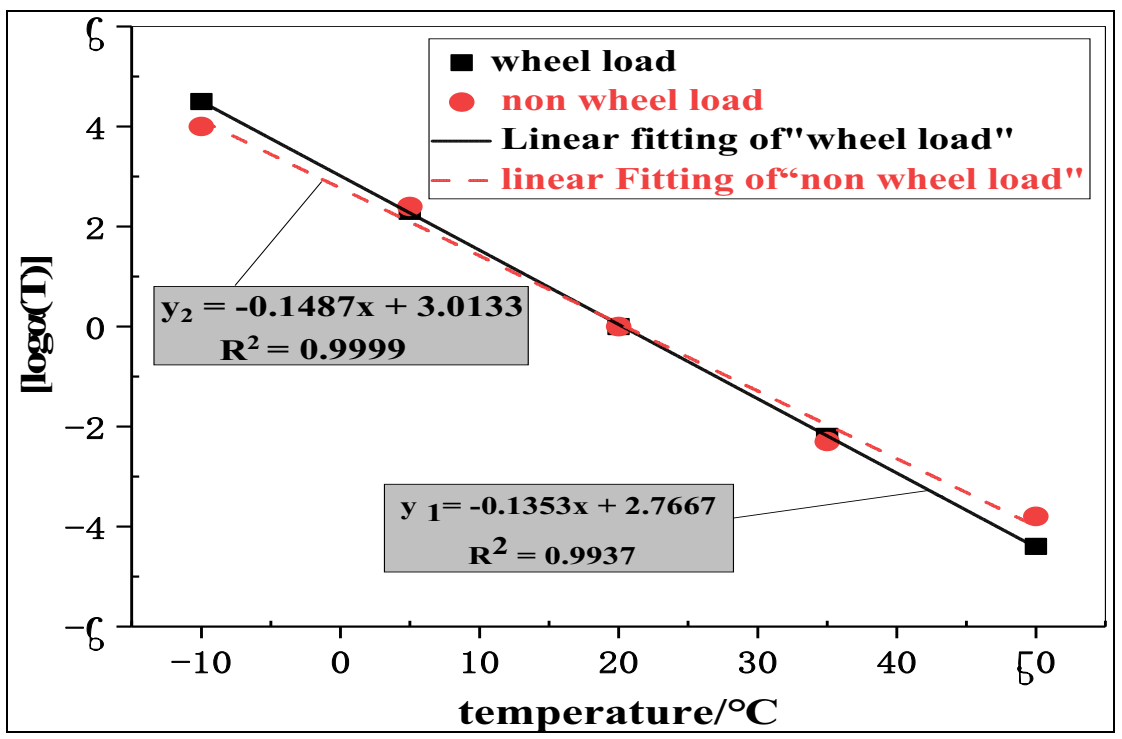

Figure 3. Displacement factor of each temperature modulus curve translation to $20^{\circ} \mathrm{C}$

\section{2 master curves of dynamic modulus}

\subsection{1 principal curve model}

According to the time-temperature superposition principle, the mechanical properties of asphalt mixture varying with loading frequency at different temperatures can be fitted into a smooth "S" curve by horizontal translation, which is called the main curve, and the translation distance is the displacement factor $\log [\alpha(T)]$.

$$
\log [\alpha(T)]=\log f_{r}-\log f
$$

Where: $f_{r}$-the loading frequency at the reference temperature; $f$ - the loading frequency at the converted temperature.

Because of its extreme, it is difficult to obtain a large number of accurate test data at low temperatures. In this paper, the displacement factor $\log [\alpha(\mathrm{Ti})]$ at each temperature is obtained by fitting the $\log [\alpha(T)]$ function curve, and the relationship between the mixture modulus E and frequency $f$ is expressed by fitting the sigmoidal function model ${ }^{[14]}$.

$$
\lg E=A_{2}+\frac{A_{1}}{1+e^{\alpha+\gamma \mathrm{lg} f}}
$$

Where: $A_{1} 、 A_{2} 、 \alpha, \gamma$ are all regression coefficients.

It can be seen from Figure 3 that there is a linear relationship between displacement factor and temperature. The dynamic modulus curve of each temperature shifts $\log [\alpha(\mathrm{Ti})]$ unit. After fitting by the sigmoidal curve, that is, according to sigmoid model and time-temperature superposition principle, the dynamic master curve of asphalt mixture before and after wheel load can be obtained, as shown in Figure 4 and figure 5 respectively.

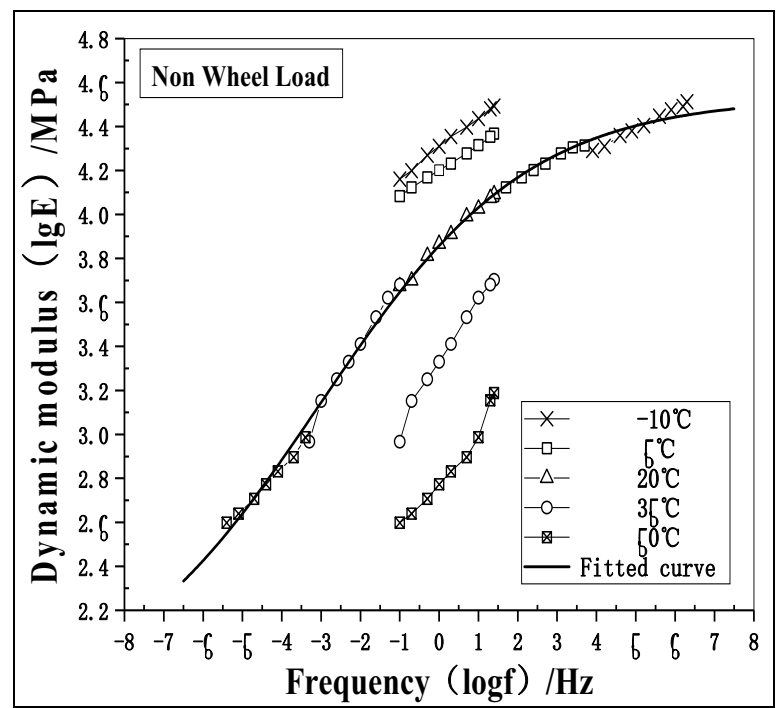

Figure 4. The master curve of AC-20 before wheel load at $20^{\circ} \mathrm{C}$

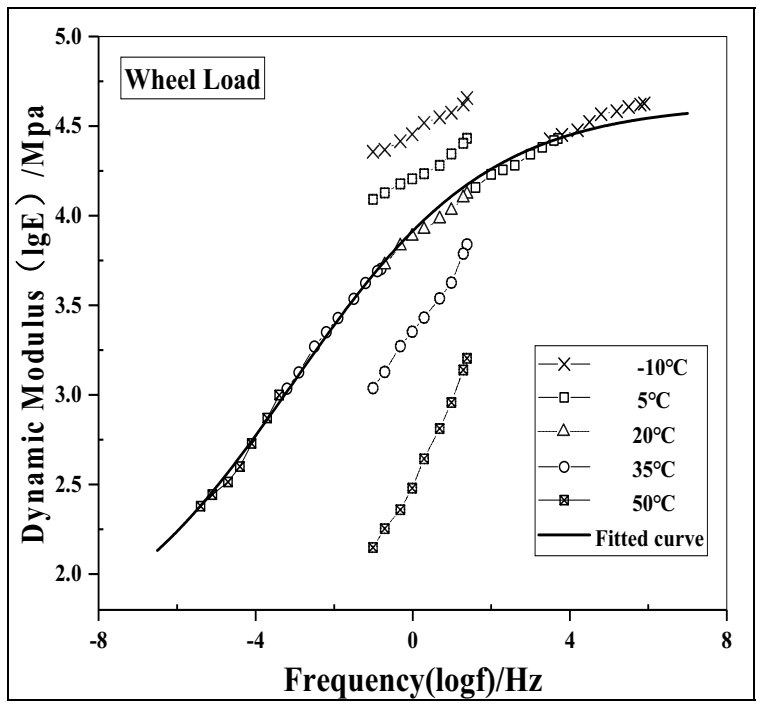

Figure 5. The master curve of AC-20 after wheel load at $20^{\circ} \mathrm{C}$

According to the time-temperature superposition principle, the mechanical properties of viscoelastic 
medium under high-temperature low-frequency and lowtemperature high-frequency conditions are similar. Therefore, when the mixture is loaded with high frequency, it will show more consistent material properties with the low-temperature conditions. From this, the corresponding low-temperature properties of the tested mixture can be calculated according to the high temperature tested results of each frequency.

Through the calculation of displacement factor function, the master curves of the mixture after accelerated loading test fatigue and the conventional mixture at $20^{\circ} \mathrm{C}$ are horizontally shifted by 5.5 and 6.0 units respectively, and the master curves at $-20^{\circ} \mathrm{C}$ before and after wheel load fatigue are obtained respectively, as shown in Figure 6; the prediction models are respectively as follows (3) and (4).

Non-wheel load: $\lg \mathrm{E}=3.84445-\frac{1.22498}{1+e^{0.57456+0.90659 \lg f}}$ (3)
Wheel load: $\lg \mathrm{E}^{\prime}=3.51161-\frac{1.17267}{1+e^{0.23099+0.73752 \lg f}}$

Where: E-dynamic modulus/MPa; $f$-loading frequency/Hz.

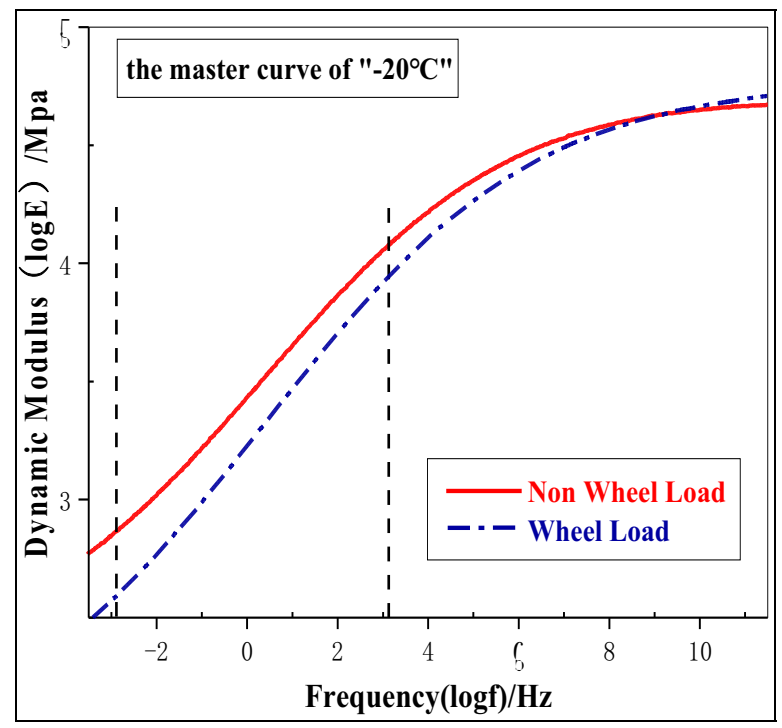

Figure 6. Comparison of master curve of mixture at $-20^{\circ} \mathrm{C}$

As for the master curve at $-20^{\circ} \mathrm{C}$, the dynamic modulus value of the mixture without wheel load is much higher than that of the mixture after wheel load, and the maximum difference is $\left(10^{4} \mathrm{MPa}-10^{3.78} \mathrm{MPa}\right)$, that is $3974 \mathrm{MPa}$; however, the relative attenuation of dynamic modulus after wheel load (dynamic modulus after wheel load / dynamic modulus before wheel load) decreases gradually, so it is necessary to further explore whether there is a certain regularity in this phenomenon.

\subsubsection{Dynamic modulus ratio analysis}

By comparing the dynamic modulus master curve of asphalt mixture before and after accelerated loading, it is found that the dynamic modulus changes differently with the reduction frequency and the difference is larger in the frequency range of $10^{-2} \mathrm{~Hz} \sim 10^{4} \mathrm{~Hz}$. In addition, the road surface time of most vehicle loads on service roads is in the range of $10^{-3} \mathrm{~s} \sim 10^{2} \mathrm{~s}$. Refer to the formula $t=1 / 2 \pi f$ of van der Poe, select each point in the frequency range to draw the dynamic modulus ratio diagram, as shown in Figure 7 , in which the dynamic modulus ratio is defined as:

$$
k=\frac{E^{\prime}}{E}
$$

Where: $k$-dynamic modulus ratio; $E^{\prime}$-dynamic modulus after wheel load; E-dynamic modulus before wheel load.

The relationship between the dynamic modulus ratio and the reduced frequency is more consistent with the quartic function in the range of $10^{-3} \mathrm{~s} \sim 10^{2} \mathrm{~s}$ (converted frequency $\left.1.6 \times 10^{-3} \sim 1.6 \times 10^{2} \mathrm{~Hz}\right)$ after several trial calculations and fitting, as shown in equation (6).

$$
\begin{aligned}
\mathrm{k}=0.48833-0.0261 f+0.01024 f^{2}-0.00109 f^{3}- \\
0.000667532 f^{4}, \quad \mathrm{R}^{2}=0.99734
\end{aligned}
$$

With the increase of frequency, the dynamic modulus ratio of asphalt mixture before and after fatigue decreases, which conforms to the change rule of the model above. Combine the "Dynamic Modulus Ratio Model" with the "Non-wheel Loaded Mixture Dynamic Modulus Master Curve Model", that is, $E^{\prime}=k E$ can predict the dynamic modulus value of the mixture after the accelerated loading test better, and reduce the experimental cost under certain circumstances.

After accelerated loading, the dynamic modulus of SBS modified asphalt mixture decreases sharply at a lower frequency (or high temperature), while the dynamic modulus changes relatively little at higher frequency (or low temperature), and the difference between the highest ratio and the lowest ratio is nearly $17 \%$. The reason may be that under the action of high frequency, the time of vehicles acting on the pavement is shorter, so the damage to the pavement is smaller. Under the action of low temperature, the viscosity of asphalt is higher, and the asphalt has a greater contribution to the strength of the mixture than the aggregate skeleton, so the change of dynamic modulus before and after accelerated loading is relatively small. Therefore, the accelerated loading of 500,000 axle times has a more significant effect on the viscoelastic properties of asphalt mixture at low frequency (or high temperature), and this kind of mixture is suitable for pavement design and application in cold regions. 


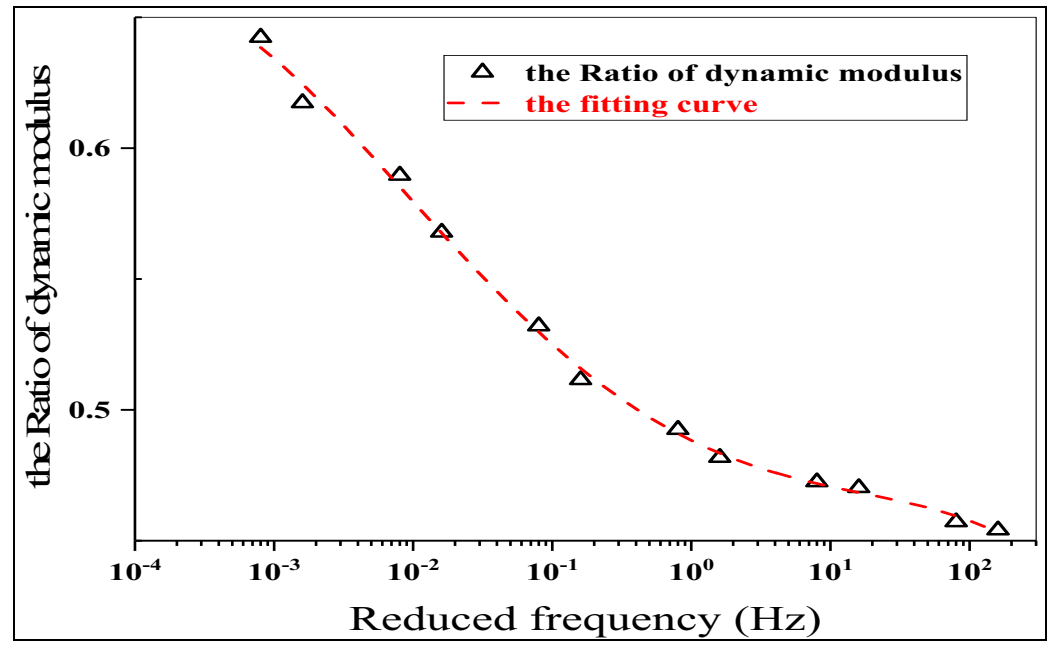

Figure 7. Variation Trend of dynamic modulus ratio of the mixture with frequency

\section{Conclusion}

The cost of measuring the dynamic modulus of asphalt mixture after fatigue is too high due to the expensive equipment for accelerated loading and dynamic modulus testing, complicated specimen production and testing process, and long time-consuming issues. Therefore, on the basis of a large number of test data, it is necessary to establish an appropriate mathematical model to predict the dynamic modulus of asphalt mixture. Through research, the conclusions are as follows.

(1) Under the action of 500000 times of axle load in the accelerated loading test, the dynamic modulus of the mixture before and after the wheel load tends to be gentle in the high-frequency range, and the sensitivity of the mixture is higher in the low-frequency state.

(2) Fitting the dynamic modulus function curve before and after $-20^{\circ} \mathrm{C}$ wheel load can accurately predict the lowtemperature mechanical properties of asphalt mixture materials and save the test cost.

(3) By fitting the dynamic modulus ratio frequency function, the dynamic modulus value of asphalt mixture after accelerated loading test can be expressed as follows: the impact of 500,000 times of accelerated loading on the viscoelastic properties of asphalt mixture at low frequency (or high temperature) is the most significant; and the dynamic modulus value of the mixture after 500,000 times of axle load can be predicted by using " $E^{\prime}=k E$ ".

\section{Reference}

1. J. Yu, Construction and test of American Western Ring Road. J. Foreign Highway, 19, 56-57(1999) (in Chinese).

2. O. Sirin, M. Tia, R. Roque, B. Choubane, Evaluation of performance characteristics of the heavy vehicle simulator in Florida. J. Build Environ, 42, 12701277.(2007)

3. B. Choubane, S. Gokhale, et al. Evaluation of coarse and fine graded superpave mixtures under accelerated pavement testing. J. Transport Res Rec, 1974, 120-
127.(2006)

4. Y. Tang, J. Li, Study on fatigue damage evolution law of Asphalt Pavement based on biaxial accelerated loading test .R. Jinan: Shandong Jiaotong University, 2014.12.(2004) (in Chinese)

5. Guo Runhua, Prozzi Jorge A. Calibrating the aging difference between in-service fatigue performance of flexible pavements and accelerated pavement testing[C]. Proceedings of the 2006 Airfield and Highway Pavement Specialty Conference, 2006: 98106.(2006)

6. M. O. Marasteanu, et al. Dynamic and Resilient Modulus of Mn /DOT Asphalt Mixtures [R]. Minneapolis: University of Minnesota. 2003.

7. D.C. Wang, Research on Influencing Factors of dynamic modulus of asphalt mixture. $\mathrm{J}$ Inner Mongolia Highway and Transport, 1-5+63.(2016) (in Chinese)

8. X. Ma, F.J. Ni, R.S. Chen, Dynamic modulus test and model prediction of asphalt mixture. J. Chinese Highway, 35-39+52.(2008)(in Chinese)

9. Z.J. Huang, Experimental study on dynamic modulus of TLA modified asphalt mixture. J. China Foreign Highway, 37, 247-252.(2017)(in Chinese)

10. W.P. Wang, Study on dynamic modulus of asphalt mixture and its variation law. J. China Foreign Highway, 37, 285-288.(2017)(in Chinese)

11. J.C. Wei, S.P. Cui, J.B. Hu, Experimental study on dynamic modulus of asphalt mixture. J. Build Mater, 11, 657-661.(2008) (in Chinese)

12. R.D. Wu, W.Y. Sun, Y. Bai, L.Y. Zhang, Study on dynamic modulus of epoxy asphalt OGFC mixture based on uniaxial compression test. Highway Transport Tech, 16, 89-91.(2020) (in Chinese)

13. L. Yu, C.Y. Guo, et al. Study on dynamic modulus and main curve of rubber asphalt mixture. J. China Foreign Highway, 35, 203-207.(2015) (in Chinese)

14. Y. Xue, P.L. Li, et al. Comparative analysis of dynamic modulus master curve method of asphalt mixture. J. Guangxi University (Natural Science Edition), 45, 1-9.(2020)(in Chinese) 